\title{
Designing a Success Model for Entrepreneurs in Sports Businesses
}

\author{
${ }^{1}$ Zahra Tasaddoghi', ${ }^{2}$ Seyed Mohammad Hossein Razavi, ${ }^{1}$ Saeed Amirnezhad \\ ${ }^{1}$ Department of Sport Management, Shomal University, Amol, Iran. ${ }^{2}$ Department of Sport Management, \\ University of Mazandaran, Baboulsar, Iran.
}

Submitted 01 August 2019; Accepted in final form 10 December 2019.

\begin{abstract}
Background. Every entrepreneurial business sees its success factors differ depending on the nature of the products and services, but in any case, the success of entrepreneurship depends on a set of factors. Objectives. The purpose of this study is to design a model of entrepreneurship success in sports businesses. Methods. The research method was qualitative and the data-base method was used to analyze participants' responses. It should be noted that data collection was done by reviewing the theoretical bases and interviews. The statistical population of this study consisted of faculty members of Entrepreneurship and Sport Sciences Management Faculties specializing in Entrepreneurship and Business Management at public universities, members and lecturers of the Employment and Entrepreneurship Working Group of the Ministry of Sport and Youth and Elected Entrepreneurs in Iran. Using the data base method, the sampling was done theoretically and after 20 interviews the model framework was formed. Data analysis was performed using three stages of open, axial and selective coding. After open coding, categories including causal conditions, contextual conditions, intervening conditions, strategies and outcomes of entrepreneurs' success in sports businesses were extracted, and then in the axial and selective coding stage, the link between these categories was formulated. The research paradigm model was determined. Results. Based on the results of the study, 12 indicators were identified in causal conditions, 7 in contextual conditions, 11 in interventional conditions, 13 in strategies, and 11 in outcomes. Conclusion. Incorporating breakthrough benchmarks into managing a sports entrepreneurial business is about achieving a stronger and better position in the business environment and competing with competitors, thus keeping track of the success factors in an entrepreneurial business. The sport enables entrepreneurs to gain enough potential in the target market as well as in the field of commercial competition.
\end{abstract}

KEYWORDS: Entrepreneur, Success, Sports Business, Iran

\section{INTRODUCTION}

The entrepreneurs are considered as the backbone of the economy who play an important role in creating wealth and enhancing economic growth (1). In other words, the entrepreneur's activity is a key component of the social and economic environment of a country and hence studies on entrepreneurship in order to develop tools, techniques, procedural mechanisms, and etc. to facilitate the understanding and development of the entrepreneur's approach is very important (2). In the meantime, sport as a growing industry has many entrepreneurial opportunities in itself (3).

While, the failure of sports businesses indicates problems and challenges in the field of sports entrepreneurship, so that failure in sports businesses is abundant and the consequence will be the lack of sports institutionalization for individuals, organizations, institutions and community (4). In this regard, the researchers believe that benefiting from the entrepreneurial approach in sport enables sports businesses to

*. Corresponding Author:

Zahra Tasaddoghi, $\mathrm{PhD}$

E-mail: zahra_tasaddoghi@yahoo.com 
remain competitive and have stable success (5), the goals of this interactive program are promoting sports business performance and private sector development in the sports industry that enhances the ability of the industry through programs, events and the development of entrepreneurial activities (6). Under such conditions, the life of sports entrepreneurial businesses and the institutionalization of their success can not only lead to the economic development of countries, but also to the sustainability of sports businesses, and this will not be possible unless there is a desired environment for achieving these goals. It is important to consider this environment with regarding the role of organizations and institutions as facilitators and the core of planning (4).

In this regard, extensive studies have explained the model of entrepreneurial businesses' sustainability, some of which have identified institutional factors such as rules, norms, values, learning and innovation dimensions, and others have identified capital factors as affecting the success of entrepreneurial businesses (7). Other researchers have also examined the factors affecting the success of entrepreneurs in entrepreneurial businesses, and each has its own factors such as having sufficient capital, utilizing past failures, benefiting from emotional intelligence, motivation and ability, use of networking in the form of informal relationships found effective on understanding the rules governing business, and etc. in this regard (8). On the other hand, Park et al. (2017), in a paper entitled "Investigating the Factors Affecting the Success or Failure of IT Services Market in Korea", analyzed the success of IT services mainly due to the customer needs, low investment costs, existing competition, ecosystem support and active marketing activities and identified the lack of a viable business model as not having significant success, and introduced government policies affecting the success or failure of these services. It should be noted that the success or failure of IT services businesses has a significant effect on the national economy and customer welfare (9). Also, Stanowski (2016), in a study entitled "Contribution of Business Experience and Knowledge to Entrepreneurial Success", concluded that entrepreneurs with high management experience and unique knowledge with the benefit of knowledgeable employees had higher mean scores for the index of entrepreneurial success (10). As well as Langevin and DanoverAwitz (2015), in a study entitled "Factors Affecting Business Model Success in the Hospitality Services Industry" concluded that business success in the hospitality services industry depends on creating value for the customer, applying innovations in the processes of service delivery, and establish close relationships with other partners in the desired industry sector as well as the customer (11).

In addition, Ayala and Manzano (2014), in a paper entitled "Entrepreneurial Flexibility and Influencing Business Success (Longitudinal Analysis)", concluded that three dimensions of flexibility (hardness, ability, and optimism) helped predict entrepreneurial success (12). Chitti et al. (2011) also in a study entitled "Investigating the Factors Affecting the Business Success of Small and Medium Enterprises (SMEs) in Thailand" concluded that the customer and supplier relationships, business management and collaboration, access to financial and nonfinancial resources, and finally the external environment can be critical to the success of an entrepreneurial business (13). As well as Jasra et al. (2011), in a study entitled "Determinants of SME Business Success", considered financial resources, technological resources, entrepreneurial skills, government support, marketing strategy, quality of business planning and access to Information effective on the success of entrepreneurial businesses (14) and finally Salome et al. (2013), in a study titled "Investigating the Factors Affecting Sporting Businesses' Sustainability" considered factors such as personal and managerial attitudes and values, gaining competitive advantage and promoting credibility as factors that contribute to sports entrepreneurs' willingness to sustainability (15).

Studies that to date have been conducted by various researchers to describe and predict entrepreneurial success, although using different levels of analysis have provided a better understanding of entrepreneurial success, have yet to come up with a common definition of entrepreneurial success (2). And in many published works, the success of entrepreneurial businesses has only been analyzed externally, including the support or lack of support of government, banks, or legal systems and while the success in entrepreneurial businesses is a set 
of internal and external factors related to entrepreneurship that need to be considered together (8). According to the above, identifying the factors that influence entrepreneurs' success in sports businesses is vital to empowering sports entrepreneurs. However, despite this necessity, few studies have been conducted on the success of entrepreneurs in sports businesses. Few existing studies have been conducted using quantitative methods and questionnaire tools and have been surveyed with little validity for describing and predicting the reasons for entrepreneurs' success. So, the researcher in the present study will attempt to design a model of entrepreneurial success in sports business through a qualitative study.

\section{MATERIALS AND METHODS}

Regarding the nature and objectives of the present study and the lack of comprehensive and complete research on the success of entrepreneurs in sports businesses, a systematic study of databased theory (a qualitative research method), was conducted according to Strauss and Corbin (1998) to examine real data in order to identify important variables in the context of entrepreneurial success in sports businesses. In this regard, in order to collect data, library studies (document review) and in-depth interviews were used.

The statistical population of the present study consisted of faculty members of the Departments of Entrepreneurship and Sport Sciences with the specialty of Entrepreneurship and Business Management at public universities, members and professors of the Employment and Entrepreneurship Working Group of the Ministry of Sport and Youth and Elected Entrepreneurs in Iran. The sampling method was theoretical and using a judgmental method in which the research team attempted to select samples based on what specific information is needed. In the data-based method, the researcher asks the first participant, usually selected easily, to introduce others with experiences and perspectives in the field of study to participate in the study that is a chain or snowball sampling method. It should be noted that the criterion for judging when to stop sampling was theoretical saturation.

The interview questions were designed based on Strauss and Corbin's (1998) paradigmatic model and systematic approach. The questions were also asked based on the participants' responses to explore specific and deeper aspects of the studied topic, and finally all interviews ended with the open question "Do you think there is something you haven't said?" The interviews lasted between 30 and 90 minutes, all recorded by a digital recorder. Prior to the interview and to maximize the participation of the sample, a letter was sent to the participants by email detailing the objectives of the study and related questions and asking them to meet in person.

An edit approach to data arising theory was used to analyze the interviews. For this purpose, software NVIVO was used. In fact, the edit approach aims at meaningful parts (for analysis in the interview), seeking to increase or reduce words or sentences and eliminate unnecessary words in the text. In this regard, open coding is an analytical process through which the concepts of identification and its features and dimensions are discovered in the data, and the central coding is the process of linking categories and subcategories at the level of features and dimensions (16).

In fact, the concepts and categories derived from the open coding stage are embedded in the coding paradigm, the coding paradigm delineates the relationships between categories such as causal conditions, contextual conditions, axial categories, confounding conditions, strategies, and outcomes, and finally selective coding is a process that leads to integration and improvement of categories.

The causal conditions are a set of conditions that cause the phenomenon to emerge, grow, and expand, the contextual conditions are the conditions within which the phenomenon is located, and the intermediate conditions are the broad context that affects the particular conditions of the phenomenon. The strategies are categories for controlling and dealing with the studied phenomenon, and the consequences are the result of the strategies for controlling and addressing the phenomenon.

This study aimed to increase the internal validity by providing feedback to the interviewees and placing them on the research path so as not to affect their responses. In the meantime, after each interview, information were obtained until that stage was presented and discussed if the interviewee considered the points. This was done after the interview so that the interview was free of any assumptions and orientations. In addition, four other activities were undertaken to increase the internal validity of the results:

1. Using different sources to collect data 
2. Check data by an assistant

3. Participation of a specialist familiar with the data-base research method

4. Identify orientations through asking frequently asked questions while analyzing data

Also, for the reliability of the study, independent coding of the results of the interviews of participants was done randomly by a person with no subject background. In this regard, in order to measure the quality of the encodings, the agreement between the two coders based on Kappa coefficient was used. Therefore, it can be claimed that the coding process was sufficiently reliable.

\section{RESULTS}

The design of the Entrepreneurs' Success Model for Sporting Businesses was based on data from the analysis of 20 semi-structured interviews, and the categories, subcategories, and codes (concepts) are given in Table 2. Table 1 also shows the distribution of individuals in the groups participating in the interview.

\section{Table 1. Distribution of Individuals in Interview Participant Groups}

\begin{tabular}{|c|c|c|}
\hline Row & Specialty & Number \\
\hline 1 & Member of Faculty of Entrepreneurship Management & 3 \\
\hline & Faculty Member of Faculty of Physical Education and Sport Sciences with specialty of Entrepreneurship and Business & \\
\hline 2 & $\begin{array}{l}\text { Management and Special Lecturer and Elected Working Group on Employment and Entrepreneurship of Ministry of Sport } \\
\text { and Youth of the Islamic Republic of Iran }\end{array}$ & 4 \\
\hline 3 & $\begin{array}{l}\text { Sport Entrepreneur and Faculty of Physical Education and Sport Sciences with Entrepreneurship and Business Management } \\
\text { Specialty }\end{array}$ & 1 \\
\hline 4 & $\begin{array}{l}\text { Sport Entrepreneur and Special and Selected Teacher of the Employment and Entrepreneurship Working Group of Ministry } \\
\text { of Sport and Youth of the Islamic Republic of Iran }\end{array}$ & 5 \\
\hline 5 & $\begin{array}{l}\text { Faculty Member of the Faculty of Physical Education and Sport Sciences with Entrepreneurship and Business Management } \\
\text { Specialty }\end{array}$ & 2 \\
\hline 6 & National Sports Entrepreneur (Iran) & 5 \\
\hline 7 & Total & 20 \\
\hline
\end{tabular}

Table 2. Second Level Axial Coding Results (Categorization)

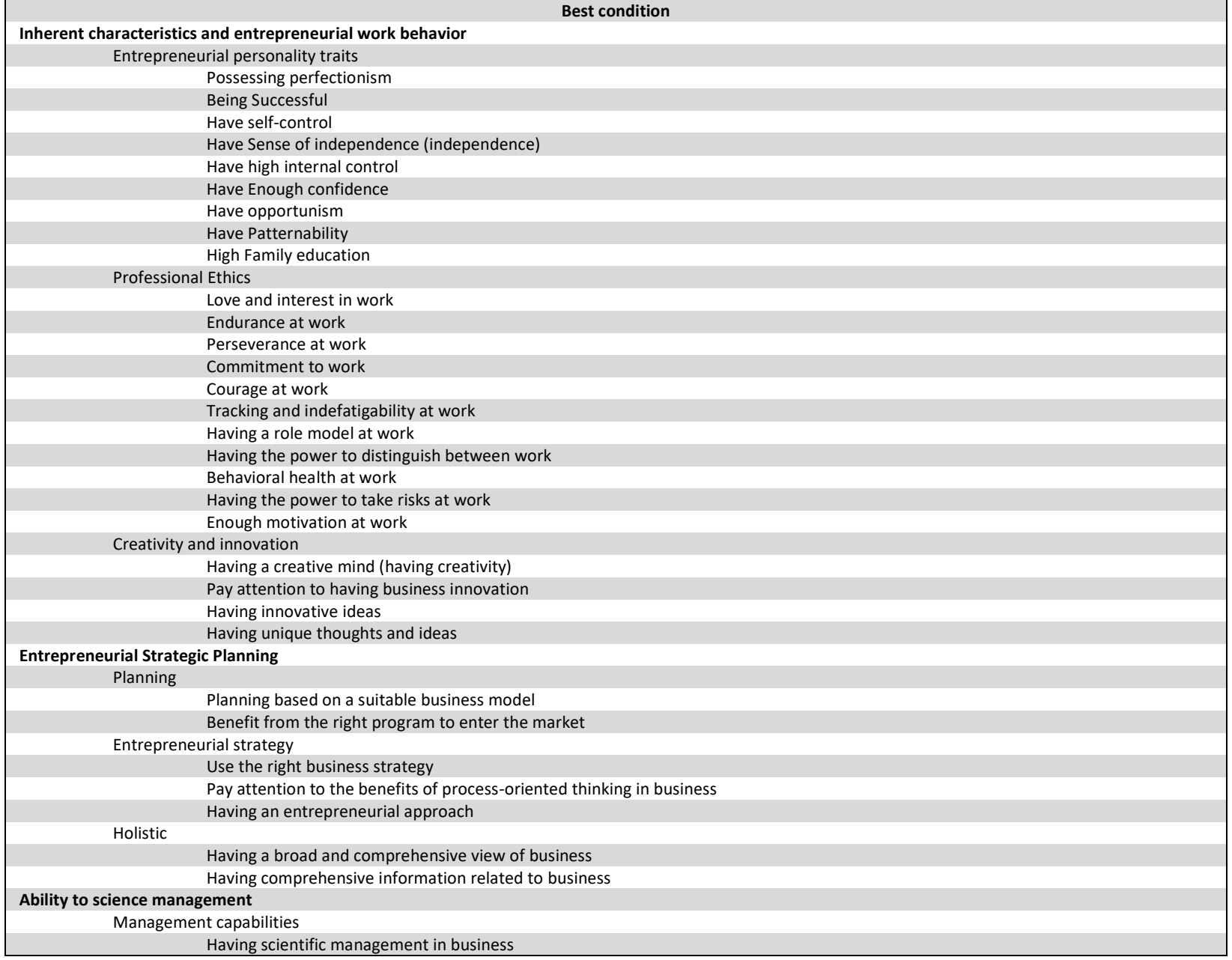




\begin{tabular}{|c|c|}
\hline & Having efficient business management \\
\hline & Having a leadership-like management (entrepreneurial leadership) \\
\hline & Benefit from inclusive quality management methods \\
\hline & Self-management ability \\
\hline & Ability to manage time \\
\hline & Ability to manage risk \\
\hline \multicolumn{2}{|c|}{ Expertise and scientism } \\
\hline & Having scientific abilities \\
\hline & Pay attention to scientific issues in business \\
\hline & Enough expertise \\
\hline & Having specialized knowledge in business \\
\hline & Having a business-related education \\
\hline & Having business-related legal knowledge \\
\hline & Team building (having a strong and specialized team) \\
\hline \multicolumn{2}{|l|}{ Tendency to market } \\
\hline \multicolumn{2}{|c|}{ Market Knowledge } \\
\hline & Paying attention to market assessment (accurate market monitoring) \\
\hline & Recognize the target market \\
\hline & Identify and define consumer behavior \\
\hline \multicolumn{2}{|l|}{ Marketing } \\
\hline & Creating a coherent and stable market by observing the standards \\
\hline & Marketing \\
\hline \multicolumn{2}{|c|}{ Environmental analysis (business environment) } \\
\hline \multicolumn{2}{|c|}{ Ability to analyze environmental conditions } \\
\hline & Ability to analyze business-related external environment conditions \\
\hline & Ability to analyze business environment related conditions \\
\hline & Multi-dimensional processing power of business environment \\
\hline & Having the ability to predict the future \\
\hline & Environmental feasibility study \\
\hline \multicolumn{2}{|c|}{ Change needs } \\
\hline & Forced to change positively due to constant environmental changes \\
\hline & Continuous changes in customer needs and wants \\
\hline & Attention to needs assessment in society \\
\hline & Background conditions \\
\hline \multicolumn{2}{|l|}{ Regulatory approaches } \\
\hline \multicolumn{2}{|c|}{ Government support policies } \\
\hline & Increase government financial and spiritual support for entrepreneurial businesses \\
\hline & Granting low-interest government facilities to entrepreneurs \\
\hline & Increase the support of accelerator and investor companies \\
\hline & Providing the right environment for entrepreneurship \\
\hline \multicolumn{2}{|c|}{ Government support institutions } \\
\hline & $\begin{array}{l}\text { Establish an institution for greater coordination between the Ministry of Sports and Youth and other institutions related to } \\
\text { entrepreneurship }\end{array}$ \\
\hline & Establishment of a headquarters or working group for entrepreneurial sports businesses in the Ministry of Sports and Youth \\
\hline \multicolumn{2}{|c|}{ Legal and legal factors } \\
\hline & Having the right legal platform to start a business \\
\hline & Pay attention to the rules and regulations governing the business environment \\
\hline & Take legal action to facilitate the activities of entrepreneurs \\
\hline & Establish flexible rules in accordance with business conditions \\
\hline & Pay attention to the existence of administrative democracy in the field of business \\
\hline \multicolumn{2}{|c|}{ Facilitating policies } \\
\hline & Facilitate the activities of entrepreneurs by the government \\
\hline & Creating facilitator processes in the business environment \\
\hline & Take legal action to facilitate the activities of entrepreneurs \\
\hline & Creating an Entrepreneurship Development Ecosystem \\
\hline
\end{tabular}

The open, axial, and selective coding was performed according to the systematic approach, the information of which are given in Table 2. In fact, after the interviews were entered software NVIVO, the open coding process was performed by dividing the assembled collection into the smallest conceptual component.

In open coding, the text of the interviews was read over and over and the data became concepts, the codes at this stage were 425 codes. A closer study of the identified codes revealed that many of the codes, although referred to in different terms, have the same meaning based on the research questions raised in this study. Hence, these codes were aggregated and presented as 204 codes as the final product of open coding.

At the next stage, similar concepts were identified and categorized in a category, then subdivided into more abstract sub-categories and finally based on a paradigmatic model of causal and contextual conditions, confounders, strategies, and outcomes were linked with each of the categories and at the selective coding stage the main category was selected and its link to the other categories was identified. As shown in Table 2, among the concepts derived from the interview, 54 categories were identified and, finally, entrepreneurs' success in sports 
businesses is based on the paradigm model illustrated in Figure 1.

\section{CONCLUSION}

The results of the analysis of the data obtained from the interviews showed that in the causal conditions section, the indices were effective on entrepreneurs' success such as entrepreneurial personality, professional ethics, creativity and innovation, planning, entrepreneurial strategy, being holistic, managerial abilities, expertise and science, marketing, marketability, ability to analyze environmental conditions and changing needs, and in contextual conditions section indices such as government support policies, government support agencies, legal and regulatory factors, facilitating policies, meta organizational communications, educational and research system and cultural factors were effective on entrepreneurs' success. On the other hand, in the confounding conditions section, indices such as bad government policies, unfair competition, lack of scientific approach, noncompliance with customer needs, lack of investment, lack of companionship, economic problems, socio-cultural problems, managerial weaknesses, financial weaknesses and behavioral weaknesses have been identified as obstacles that make sports entrepreneurs difficult to succeed. Also in the Strategies section indices such as Human Resources, Financial Resources, New Technologies, Knowledge Management, Thinking, Networking, Financial Management, Branding, In-Organization Analysis, Advertising and Marketing, Needs Assessment, Customer Orientation and Qualification are suggested for Achieving Sport Entrepreneurs to Success and finally the results showed that entrepreneurial success in sports businesses had consequences such as satisfying inner sense of entrepreneur's success, entrepreneur's social state growth, brand growth, wealth creation, economic growth of the country, increasing community health rate, increasing willingness to sports, self-sufficiency, sustainable employment, entrepreneurial businesses grow sport and physical education.

In this regard, consistent with the results of the present study - in terms of causal conditions - and according to the results of a series of studies on identifying the factors affecting the success of entrepreneurial businesses, the researchers found that sufficient motivation and ability (7) and (12), Specialization, Management Style and Professional Characteristics (8), Business and
Collaboration Management (13) and (15), Applying Innovations and Creativity in Service and Product Delivery Processes (17) and (11), Long-term Planning and Entrepreneurial Strategy (17) and (14), managerial abilities, knowledge and expertise (10) and entrepreneurial personality (12) and (15) are factors that can influence the success of entrepreneurs, and these factors, along with other factors identified in this field (causal conditions), can all significantly influence the success of entrepreneurs in sports businesses.

On the other hand, consistent with the results of the present study - in the contextual conditions section - and according to the results of a series of studies on identifying the factors affecting the success of entrepreneurial businesses, the researchers found that the external business environment (13), Entrepreneurial Culture (17), Institutional Factors such as Laws, Norms and Values (7) and Entrepreneurial Ecosystem Support by Governments and Government Support Policies (9) and (14) are some of the factors that can influence the success of entrepreneurs and these factors along with other cases identified in this field (contextual conditions) can all significantly influence the success of entrepreneurs in sports businesses.

Also, consistent with the results of the present study - in the confounders section - and according to the results of a series of studies on identifying the factors affecting the success of entrepreneurial businesses, the researchers found that problems related to economic, political, social and cultural environments, governmental monopoly, lack of financial and intellectual support of the government and taxation (8), can be perceived as destructive and intrusive in this regard, and these factors, along with other cases identified in this fields (the confounders section), all can be major obstacles to the success of entrepreneurs in the sports business.

In addition, consistent with the results of the present study - in the Strategies section - and according to the results of a series of studies on identifying the factors affecting entrepreneurial success, the researchers found that attention to human resources (8) and (10), infrastructure, access to financial resources (17) and (14), Using Networking in the Form of Unofficial Relationships and Building Close Relationships with Other Partners (7) and (11), Needs Assessment and Active Marketing Activities (9) and (14), Customer Orientation and Customer 
Relationships and Providers (13) and access to finance and non-financial resources (13) and (14) are some of the factors that can influence the success of entrepreneurs and these factors along with other factors identified in this section (Strategies section) can all be specifically suggested for entrepreneurs to succeed in sports businesses.

Finally, the consequences of entrepreneurial success in sports businesses can be to increase community health and reduce health care costs, increase the tendency for sport, create sustainable employment and self-sufficiency, build and grow entrepreneurial sports businesses, and develop physical education, wealth creation, the economic growth of the country, satisfy the inner sense of entrepreneur's success, the growth of the brand and the social state of the entrepreneur that these results are consistent with the study results of researchers such as Park et al. (2017), Spaje (2009), Damirjian (2009), Rotten (2011) and Gilmore et al. (2011) (18-21).

In conclusion, it should be noted that each entrepreneurial business sees its success factors depending on the nature of the different products and services, but in any case, the success of entrepreneurship depends on a set of factors identified and discussed in the present study. The purpose of considering the indices of success in managing an entrepreneurial business is to achieve a stronger and more appropriate state in the business environment and compete with competitors, so products and services in entrepreneurial businesses should not remain without evolution.

And monitoring success factors enables entrepreneurs to gain enough potential in the target market as well as in the field of business competition. The importance of different types of indices of success is not the same for all entrepreneurial businesses. For example, a key success factor for a successful reseller may be a special sales campaign, but this key success factor may not be appropriate for businesses that are service-oriented or offer products that do not have a margin for discount. Hence, sports entrepreneurs should evaluate each of the indices of success listed in the present study according to their businesses and prioritize them based on the type of product or service they provide to their customers.

But to summarize, it should be noted that efforts are important for entrepreneurs' success in sports entrepreneurial businesses, because the economic development of any country is largely dependent on the success of entrepreneurs in entrepreneurial businesses and open the way for the human progress socially, reform the political dimension, create employment economically, and provide great value to individual and professional development and bright professional horizons. Hence, controlling the critical factors of their success will lead to success in competitive performance. These factors include precisely the fields that need special attention to business growth, because if the results from these fields are not acceptable, the entrepreneur's efforts in that period are less than expected.

\section{APPLICABLE REMARKS}

- It is suggested that sports entrepreneurs take advantage of entrepreneurial features (such as risk-taking, innovation, personal motivation, etc.) and gain comparative advantage, increase their competitive edge and increase their successful presence in the bolder market.

- It is suggested to provide the infrastructure and basic facilities needed by entrepreneurs from various government agencies and departments to make sports entrepreneurship more successful. In this context, revising, simplifying, and removing obsolete laws with the financial and moral support of the government can dramatically increase the success of entrepreneurs in sports entrepreneurship businesses.

- It is suggested there be a center for entrepreneurs in the field of sports business to provide knowledge and training on how to succeed in entrepreneurship, introduce successful entrepreneurs and identify creative and innovative initiatives in this field. In this context, it is recommended that different workshops be held for potential entrepreneurs and young entrepreneurs, identifying the roots of entrepreneurial success, learning how to cope with failure, and empirical lessons learned from successes.

\section{REFERENCES}

1. Diallo B. Entrepreneurship and genetics: New Evidence. J Busin Vent Insights. 2019;11:e00123. doi: 10.1016/j.jbvi.2019.e00123 
2. Gorgiveski MJ, Ascalon EM. Entrepreneurial success: What it means to different type of entrepreneurs. European conference on work and organizational psychology; Istanbul, Turkey2006.

3. Kellett P, Russell R. A comparison between mainstream and action sport industries in Australia: A case study of the skateboarding cluster. Sport Manage Rev. 2009;12(2):66-78. doi: 10.1016/j.smr.2008.12.003

4. Mondalizade Z, Ehsani M, Honari H. Developing Sustainable Entrepreneurship Model in Sport Based on the Grounded Theory. J Sport Manage. 2016;8(5):709-725.

5. Kamukama N, Ahiauzu A, Ntayi JM. Intellectual capital and performance: testing interaction effects. $J$ Intellect Capital. 2010;11(4):554-574. doi: 10.1108/14691931011085687

6. Ruvio A, Rosenblatt Z, Hertz-Lazarowitz R. Entrepreneurial leadership vision in nonprofit vs. for-profit organizations. Leadersh Q. 2010;21(1):144-158. doi: 10.1016/j.leaqua.2009.10.011

7. Farmer J, Prior M, Taylor J. A theory of how rural health services contribute to community sustainability. Soc Sci Med. 2012;75(10):1903-1911. doi: 10.1016/j.socscimed.2012.06.035 pmid: 22901674

8. Pletnev D, Barkhatov V. Business Success of Small and Medium Sized Enterprises in Russia and Social Responsibility of Managers. Proc Soc Behav Sci. 2016;221:185-193. doi: 10.1016/j.sbspro.2016.05.105

9. Park J-H, Kim YB, Kim M-K. Investigating factors influencing the market success or failure of IT services in Korea. Int J Inf Manage. 2017;37(1):1418-1427. doi: 10.1016/j.ijinfomgt.2016.10.004

10. Staniewski MW. The contribution of business experience and knowledge to successful entrepreneurship. J Busin Res. 2016;69(11):5147-5152. doi: 10.1016/j.jbusres.2016.04.095

11.Langvinienė N, Daunoravičiūtė I. Factors Influencing the Success of Business Model in the Hospitality Service Industry. Proc Soc Behav Sci. 2015;213:902-910. doi: 10.1016/j.sbspro.2015.11.503

12. Ayala J-C, Manzano G. The resilience of the entrepreneur. Influence on the success of the business. A longitudinal analysis. J Econ Psychol. 2014;42:126-135. doi: 10.1016/j.joep.2014.02.004

13. Chittithaworn C, Islam MA, Keawchana T, Muhd Yusuf DH. Factors Affecting Business Success of Small \& Medium Enterprises (SMEs) in Thailand. Asian Soc Sci. 2011;7(5). doi: 10.5539/ass.v7n5p180

14.Jasra J, Hunjra AI, Rehman AU, Azam RI, Khan MA. Determinants of business success of small and medium enterprises. Int J Busin Soc Sci. 2011;2(20).

15. Salome LR, van Bottenburg M, van den Heuvel M. 'We are as green as possible': environmental responsibility in commercial artificial settings for lifestyle sports. Leis Stud. 2013;32(2):173-190. doi: $10.1080 / 02614367.2011 .645247$

16. Glaser BG. The grounded theory perspective: Conceptualization contrasted with description. J Sociol. 2001;9(145-148).

17.Fellnhofer K. Drivers of innovation success in sustainable businesses. J Clean Prod. 2017;167:15341545. doi: 10.1016/j.jclepro.2017.08.197

18. Demirdjian Z. Social entrepreneurship: Sustainable solutions to societal problems. J Am Acad Busin 2007;11(1):1-2.

19. Gilmore A, Gallagher D, O’Dwyer M. Is Social Entrepreneurship an Untapped Marketing Resource? A Commentary on its Potential for Small Sports Clubs. J Small Busin Entrepreneursh. 2012;24(1):11-15. doi: 10.1080/08276331.2011.10593522

20. Ratten V, Ratten H. International sport marketing: practical and future research implications. $J$ Busin Ind Market. 2011;26(8):614-620. doi: 10.1108/08858621111179886

21. Spaaij R. The glue that holds the community together? Sport and sustainability in rural Australia. Sport Soc. 2009;12(9):1132-1146. doi: 10.1080/17430430903137787 